\title{
Empirical Formulae to Calculate the Half-life of E1 Gamma Transitions for Selected Isotopes
}

\author{
Ali H. Ahmed* $\quad$ Muhammad Y. Ahmed*** Muhammad M. Abdulqader ${ }^{* *}$ \\ *Asst. Professor, Dept. of Physics, College of Science, Salahaddin Univ.-Erbil \\ (corresponding author), E-mail: ali.ahmed@su.edu.krd \\ *** Dept. of Physics, College of Science, Salahaddin Univ.-Erbil
}

\begin{abstract}
In the present work, the mass number $(\mathrm{A})$, gamma decay energy $\left(\mathrm{E}_{\gamma}\right)$, and half-life $\left(\mathrm{T}_{1 / 2}\right)$ of $\mathrm{E} 1$ gamma-transitions data taken from the nuclear data centers for the isotopes $\left({ }_{22} \mathrm{Ti}^{48},{ }_{21} \mathrm{Sc}^{46},{ }_{25} \mathrm{Mn}^{56},{ }_{26} \mathrm{Fe}^{59},{ }_{36} \mathrm{kr}^{87},{ }_{33} \mathrm{As}^{81}\right)$ have been used to find empirical formulae for calculating the half-life $\left(T_{1 / 2}\right)$ of such transitions. Two new established empirical formulae combines the gamma transition energies with the asymmetry factor (N-Z)/A in the first formula and the binding energy in the second formulae. A good agreement has been recorded for the experimental half-life taken from ENSDF and ENDF with those evaluated using the established formulae. In both cases the calculated half-life was in good agreement with the declared experimental data.
\end{abstract}

\section{Keywords: Empirical Formulae, Gamma Transitions, Asymmetry Factor,}

\section{Binding energy.}

\section{Introduction}

The gamma ray transition occurs when a nucleus changes from an excited state to the ground state or another excited of lower energy, as a result gamma ray photons emitted. All Gamma rays emitted by a certain nucleus are monoenergetic, i.e. they have well defined energies. The most obvious, and the most common, transition is by the emission of EM radiation. [1 and 2]

Frequently the transition does not proceed directly from an upper state to the ground state but may go in several steps involving intermediate excited state. All the process just described we call gamma transition, although only in the first is a gamma ray emitted by the nucleus. All characterized by a change in energy without change in $\mathrm{Z}$ and $\mathrm{A}$.

For gamma transition from initial state of total angular momentum $I_{i}$ and parity $\pi_{i}$ to a final state of total angular momentum $\mathrm{I}_{\mathrm{f}}$ and parity $\pi_{\mathrm{f}}$, describes by the equation

$$
\left|I_{i}-I_{f}\right| \leq L \leq\left|I_{i}+I_{f}\right| \quad \text { for }(L \neq 0)
$$


where $\mathrm{L}$ is the angular momentum of the gamma transition, the parity change is directly related to $\mathrm{L}_{\gamma}$, and for Electric multiple radiation, [1]

$$
\pi_{\mathrm{r}}(\mathrm{EL})=(-1)^{\mathrm{L}}
$$

The rapidity of decay of a particular radioactive is usually measured by the half-life $\mathrm{T}_{1 / 2}$, the half-life is readily obtained in terms of $\lambda$ (gamma decay constant) as

$$
\mathrm{T}_{1 / 2}=\ln 2 / \lambda
$$

Theoretical semiclassical was previously tried to estimate the gamma-decay constant. Weisskopf uses his nuclear statistical model to evaluate the gamma-decay widths of different electric and magnetic pole transitions. In these equations the half-life dependence on mass number (A) of each nucleus and the gamma transition energy $\left(E_{\gamma}\right)$ were formulated. To develop these formulae and calculating the gamma-transition half-life in easier way, new formulae that contain different physical term and quantity (mass number (A), binding energy (BE) and Asymmetric factor (N-Z)/A) have been tried for six nuclei $\left({ }_{22} \mathrm{Ti}^{48},{ }_{21} \mathrm{Sc}^{46}\right.$, $\left.{ }_{25} \mathrm{Mn}^{56},{ }_{26} \mathrm{Fe}^{59},{ }_{36} \mathrm{kr}^{87},{ }_{33} \mathrm{As}^{81}\right)$ in a specific gamma energy range (1-3 MeV).

\section{Data Reduction and Analysis}

Gamma decay of an excited nucleus require some time, just like the decay of an excited atom.

Nuclear excited states have half-lives for gamma emission ranging from $10^{-16} \mathrm{sec}$ to longer than 100 years.

The theory of gamma ray emission is based on the model of an electromagnetic multipole. Such a multipole may change its electric or magnetic momentum by emission of EM radiation. Consequently, electric multipole radiation (E) and magnetic multipole radiation (M) are distinguished. The quantum number (L) of the nuclear angular momentum may change by one or several units, and because of the conservation of momentum, $\mathrm{L}$ is an integer $(\mathrm{L}=1,2,3, \ldots \ldots \ldots \mathrm{L} \neq 0)$ and characterized the multipole radiation:

$\mathrm{L}=1$ is the dipole radiation,

$\mathrm{L}=2$ the quadrupole radiation.

Electric and magnetic multipole radiations have different parity. Electric multipole radiation has even parity if $\mathrm{L}$ is even, and magnetic multipole radiation has even parity if L is odd... [2 and 3], then the law of conservation of parity is valid. The spontaneous decay of a nuclear state may be considered from a quantum mechanical point of view. The finite lifetime of the state causes an uncertainty in its energy.

The width $\Gamma$ is a measure of our inability to determine precisely the energy of the state (through no fault of our own-nature imposes the limit uncertainty not our measuring instrument; a state with the exact energy cannot be observed). [4 and 5] Nuclear states typically have lifetimes greater than $10^{-12} \mathrm{sec}$ corresponding to $\Gamma<$ $10^{-10} \mathrm{MeV}$. The discrete low-lying nuclear states that are populated in ordinary decays have typical separation of order of $10^{-3} \mathrm{MeV}$ and larger [4], 
$\Gamma(\mathrm{E} 1)=0.068 \mathrm{~A}^{2 / 3} \mathrm{E}_{\gamma}^{3}$

$\Gamma(\mathrm{M} 1)=0.021 \mathrm{E}_{\gamma}^{3}$

$\Gamma(\mathrm{E} 2)=4.9 \times 10^{-8} \mathrm{~A}^{4 / 3} \mathrm{E}_{\gamma}{ }^{5}$

$\Gamma(\mathrm{M} 2)=1.5 \times 10^{-8} \mathrm{~A}^{2 / 3} \mathrm{E}_{\gamma}^{5}$

The Experimental gamma decays half-life for various gamma transitions were taken from the ENSDF (Evaluated Nuclear Structure Data File) and ENDF (Evaluated Nuclear Data File) Nuclear Data Centers (NDC). The ENSDF and ENDF tabulate the total half-lives; spin parities, and branching ratios for ground and excited state for each mass number A, Figure (1).

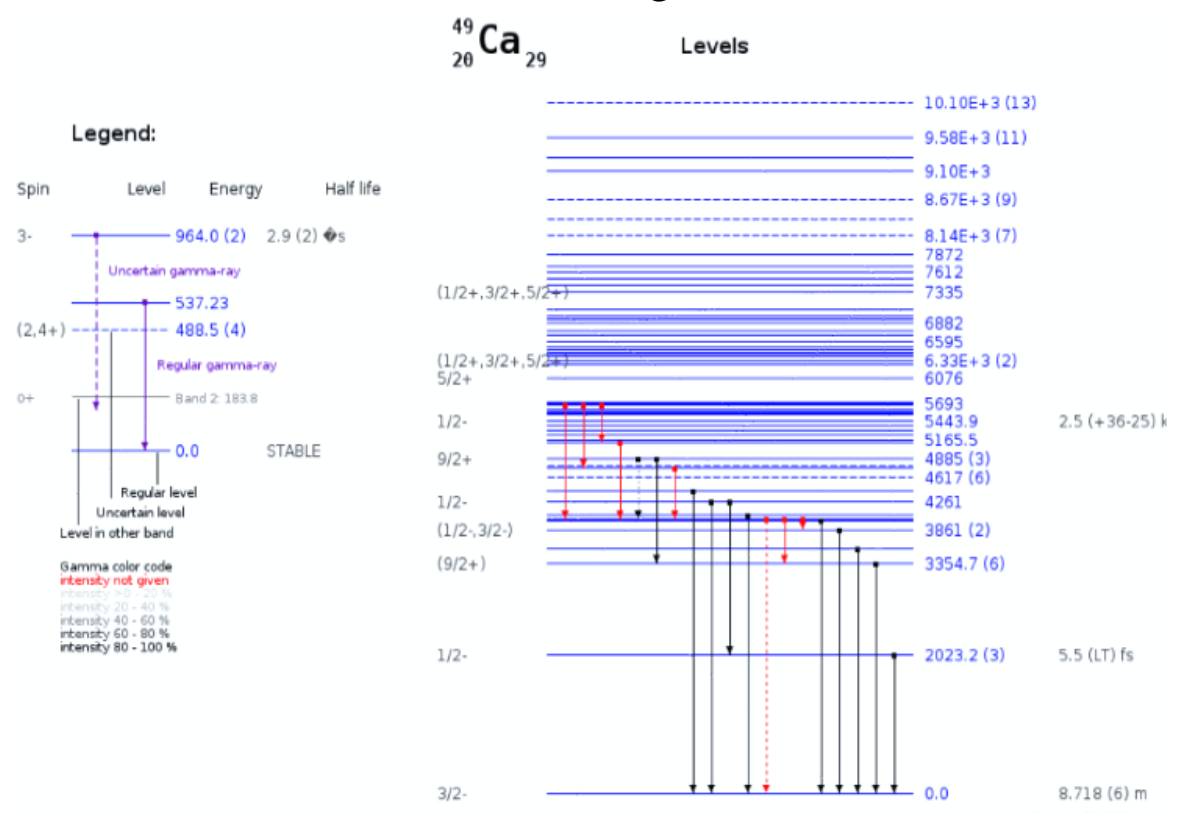

Figure (1): Typical gamma decay schemes decay excited state of a daughter nucleus.

Spins and parities of the states are indicated [6].

The experimental data of gamma transitions half-life with gamma ray energy $\left(\mathrm{E}_{\gamma}\right)$ have been plotted and fitted to a new empirical formulae. For example the gamma transitions of nucleus $\mathrm{Ca}-49$ have been fitted to a power formula as:

$$
\mathrm{T}_{1 / 2}=\mathrm{a} \mathrm{E}_{\gamma}^{\mathrm{b}}
$$

Where $\mathrm{a}$ and $\mathrm{b}$ are constant factors, and shown in Figure (2).

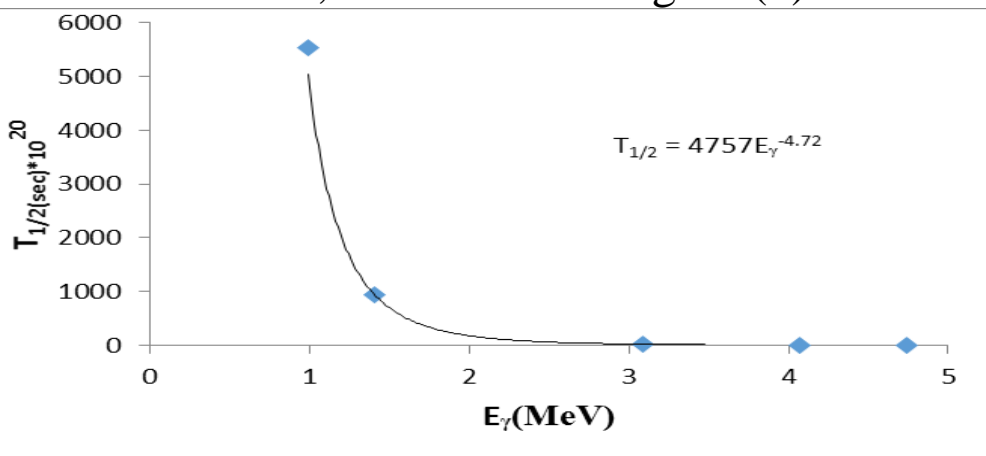

Figure (2): show the half-life is inversely proportional to the energy. 
After application of the previous power expression for the other radioactive nuclides $\left({ }_{22} \mathrm{Ti}^{48},{ }_{21} \mathrm{Sc}^{46},{ }_{25} \mathrm{Mn}^{56},{ }_{26} \mathrm{Fe}^{59},{ }_{36} \mathrm{Kr}^{87},{ }_{33} \mathrm{As}^{81}\right)$, the relation between decay half-life with the asymmetry factor $(\mathrm{N}-\mathrm{Z}) / \mathrm{A}$ have been tried for a fixed energy values within a specified energy range $(1,1.25,1.5,1.75 \mathrm{MeV}, \ldots \ldots \ldots$, $3 \mathrm{MeV}$ ) as shown in Figure (3) and given by the following power expression:

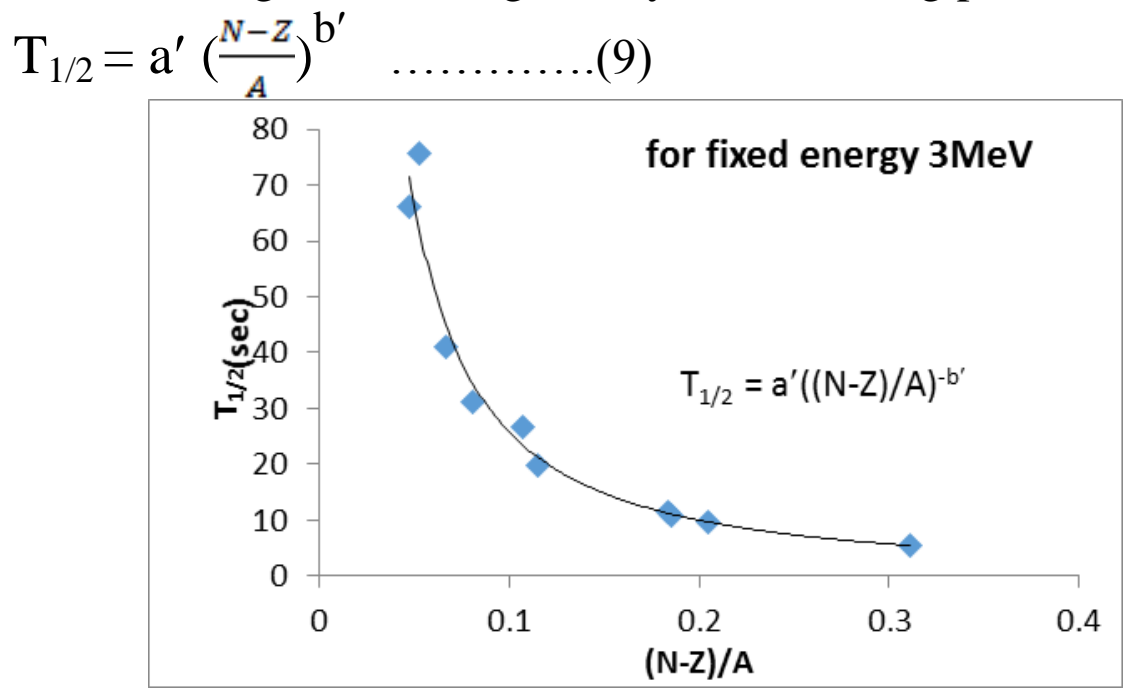

Figure (3): The decrease of half-life with the asymmetry factor (N-Z)/A. Later on, the constants $\mathrm{a}^{\prime}$ and $\mathrm{b}^{\prime}$ were plotted within the gamma energies (e.g., as shown in Figure (4) for $\mathrm{a}^{\prime}$ and fitted to the power formulae).

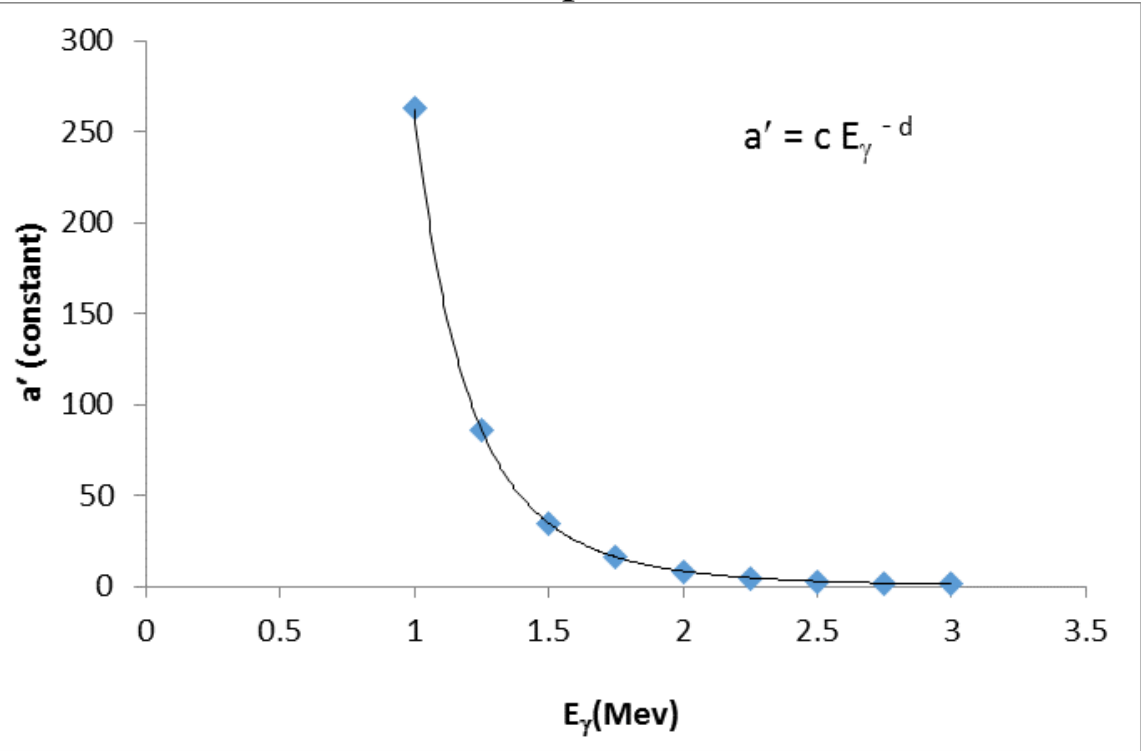

Figure (4): show this figure constant factor (a) decrease with increase fixed energy. Later on the values of constant factors ( $a^{\prime}$ and b') achieve in the empirical power formulae substitutes in formula (9). We now have new formulae contain two physical quantities which yields a new expression as a simple method to estimate the half-life:

$$
\mathrm{T}_{1 / 2}=\left(\mathrm{c} \mathrm{E}_{\gamma}^{-\mathrm{d}}\right)((\mathrm{N}-\mathrm{Z}) / \mathrm{A})^{\mathrm{e} \mathrm{E}_{\gamma}^{-\mathrm{f}} \ldots \ldots \ldots . .(10)}
$$


Thus, using this new empirical formulae, the half-life of gamma transitions for the radionuclide $\left({ }_{22} \mathrm{Ti}^{48},{ }_{21} \mathrm{Sc}^{46},{ }_{25} \mathrm{Mn}^{56},{ }_{26} \mathrm{Fe}^{59},{ }_{36} \mathrm{kr}^{87},{ }_{33} \mathrm{As}^{81}\right)$ in the energy range (1-3 $\mathrm{MeV})$ can be calculated.

\section{Results and Discussion}

\section{Energy dependence of gamma width.}

The experimental data of gamma-decay half-life's for the nucleus ${ }_{22} \mathrm{Ti}^{48}$ has been calculated from the decay schemes taken from international NDC's using the expressions:

$$
\begin{aligned}
& \Gamma(\mathrm{E} 1)=0.068 \mathrm{~A}^{2 / 3} \mathrm{E}_{\gamma}{ }^{3} \\
& \mathrm{~T}_{1 / 2}=\mathrm{h} / \Gamma
\end{aligned}
$$

for the E1 transitions as it's tabulated in Table (4-1). The obtained half-lifes then plotted against the gamma decay energy in the range $(1-3 \mathrm{MeV})$ as shown in Figure (5). The power series expression was adequate for the fitting and were tried for each nuclei with a correlation coefficient of approximately one $\left(R^{2} \cong 1\right)$,

$$
\mathrm{T}_{1 / 2}=0.5108 \mathrm{E}^{-3}
$$

with $\mathrm{R}^{2}=1$

Similarly, the former steps were applied for the other five studied nuclei $\left({ }_{21} \mathrm{Sc}^{46}\right.$, ${ }_{25} \mathrm{Mn}^{56},{ }_{26} \mathrm{Fe}^{59},{ }_{36} \mathrm{Kr}^{87},{ }_{33} \mathrm{As}^{81}$ ) as shown in Figure (5) and given in Table (1).

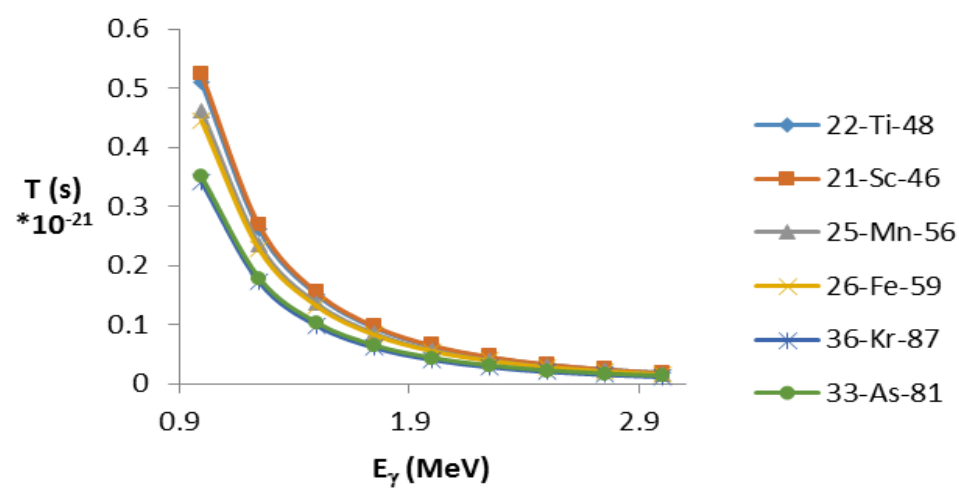

Figure (5): The energy dependence of the gamma decay half-life.

Table (1): The calculated half-life with the corresponding empirical formulae for different radionuclide's in the energy range (1-3 MeV).

\begin{tabular}{|c|c|c|c|}
\hline Nucleus & $\mathbf{T}_{\mathbf{1} / \mathbf{2}}(\mathbf{2}) * \mathbf{2 0}_{\mathbf{2 1}}^{-}$ & Formula & $\mathbf{R}^{\mathbf{2}}$ \\
\hline${ }_{22} \mathrm{Ti}^{48}$ & 0.5108 & $\mathrm{y}=0.5108 \mathrm{E}^{-3}$ & 1 \\
\hline${ }_{21} \mathrm{Sc}^{46}$ & 0.5255 & $\mathrm{y}=0.5255 \mathrm{E}^{-3}$ & 1 \\
\hline${ }_{25} \mathrm{Mn}^{56}$ & 0.4609 & $\mathrm{y}=0.4609 \mathrm{E}^{-3}$ & 1 \\
\hline${ }_{26} \mathrm{Fe}^{59}$ & 0.4452 & $\mathrm{y}=0.4452 \mathrm{E}^{-3}$ & 1 \\
\hline${ }_{36} \mathrm{Kr}^{87}$ & 0.3401 & $\mathrm{y}=0.3401 \mathrm{E}^{-}$ & 0.9963 \\
\hline${ }_{33} \mathrm{As}^{81}$ & 0.3497 & $\mathrm{y}=0.3497 \mathrm{E}^{-}$ & 1 \\
\hline
\end{tabular}




\section{Half-life and the Asymmetric Factor (N-Z)/A}

The asymmetry factor (N-Z)/A of the studied nuclei were tabulated in Table (2).

Table (2): Asymmetry factor for the studied gamma-emitting radionuclides.

\begin{tabular}{|c|c|c|c|c|}
\hline Nuclide & $\mathbf{Z}$ & $\mathbf{N}$ & $\mathbf{A}$ & $(\mathbf{N}-\mathbf{Z}) / \mathbf{A}$ \\
\hline $\mathrm{Ti}$ & 22 & 26 & 48 & 0.08333 \\
\hline $\mathrm{Sc}$ & 21 & 25 & 46 & 0.08695 \\
\hline $\mathrm{Mn}$ & 25 & 31 & 56 & 0.10714 \\
\hline $\mathrm{Fe}$ & 26 & 33 & 59 & 0.11864 \\
\hline $\mathrm{Kr}$ & 36 & 51 & 87 & 0.17241 \\
\hline $\mathrm{As}$ & 33 & 48 & 81 & 0.18518 \\
\hline
\end{tabular}

The calculated gamma-decay half-life's have been tested for the nuclei asymmetry factor $(\mathrm{N}-\mathrm{Z}) / \mathrm{A}$ dependence at the fixed gamma energy steps $(1,1.25,1.5 \mathrm{MeV}, \ldots .3$ $\mathrm{MeV}$ ) as tabulated in Table (3) and shown in Figure (6).

The plotted data have been fitted to the power expressions for each studied nuclei as

$$
\mathrm{T}_{1 / 2}=\mathrm{a}((\mathrm{N}-\mathrm{Z}) / \mathrm{A})^{-\mathrm{b}} \quad \ldots \ldots \ldots . . .(14) \quad \text { with } \mathrm{R}^{2}=0.9541-0.9818 .
$$

Table (3): Empirical formulae relating the half-life to the asymmetry factor for fixed energies (1-3MeV) with the correlation coefficient $R^{2}$.

\begin{tabular}{|c|l|c|}
\hline $\begin{array}{c}\mathbf{E}_{\gamma} \\
(\mathbf{M e V})\end{array}$ & \multicolumn{1}{|c|}{ Empirical Formula } & $\mathbf{R}^{2}$ \\
\hline 1 & $\mathrm{~T}_{1 / 2}=0.13((\mathrm{~N}-\mathrm{Z}) / \mathrm{A})^{-0.564}$ & 0.9818 \\
\hline 1.25 & $\mathrm{~T}_{1 / 2}=0.0652((\mathrm{~N}-\mathrm{Z}) / \mathrm{A})^{-0.573}$ & 0.9775 \\
\hline 1.5 & $\mathrm{~T}_{1 / 2}=0.0371((\mathrm{~N}-\mathrm{Z}) / \mathrm{A})^{-0.58}$ & 0.9734 \\
\hline 1.75 & $\mathrm{~T}_{1 / 2}=0.023((\mathrm{~N}-\mathrm{Z}) / \mathrm{A})^{-0.586}$ & 0.9696 \\
\hline 2 & $\mathrm{~T}_{1 / 2}=0.0152((\mathrm{~N}-\mathrm{Z}) / \mathrm{A})^{-0.591}$ & 0.9661 \\
\hline 2.25 & $\mathrm{~T}_{1 / 2}=0.0106((\mathrm{~N}-\mathrm{Z}) / \mathrm{A})^{-0.596}$ & 0.9628 \\
\hline 2.5 & $\mathrm{~T}_{1 / 2}=0.0076((\mathrm{~N}-\mathrm{Z}) / \mathrm{A})^{-0.6}$ & 0.9597 \\
\hline 2.75 & $\mathrm{~T}_{1 / 2}=0.0057((\mathrm{~N}-\mathrm{Z}) / \mathrm{A})^{-0.604}$ & 0.9568 \\
\hline 3 & $\mathrm{~T}_{1 / 2}=0.0043((\mathrm{~N}-\mathrm{Z}) / \mathrm{A})^{-0.607}$ & 0.9541 \\
\hline
\end{tabular}




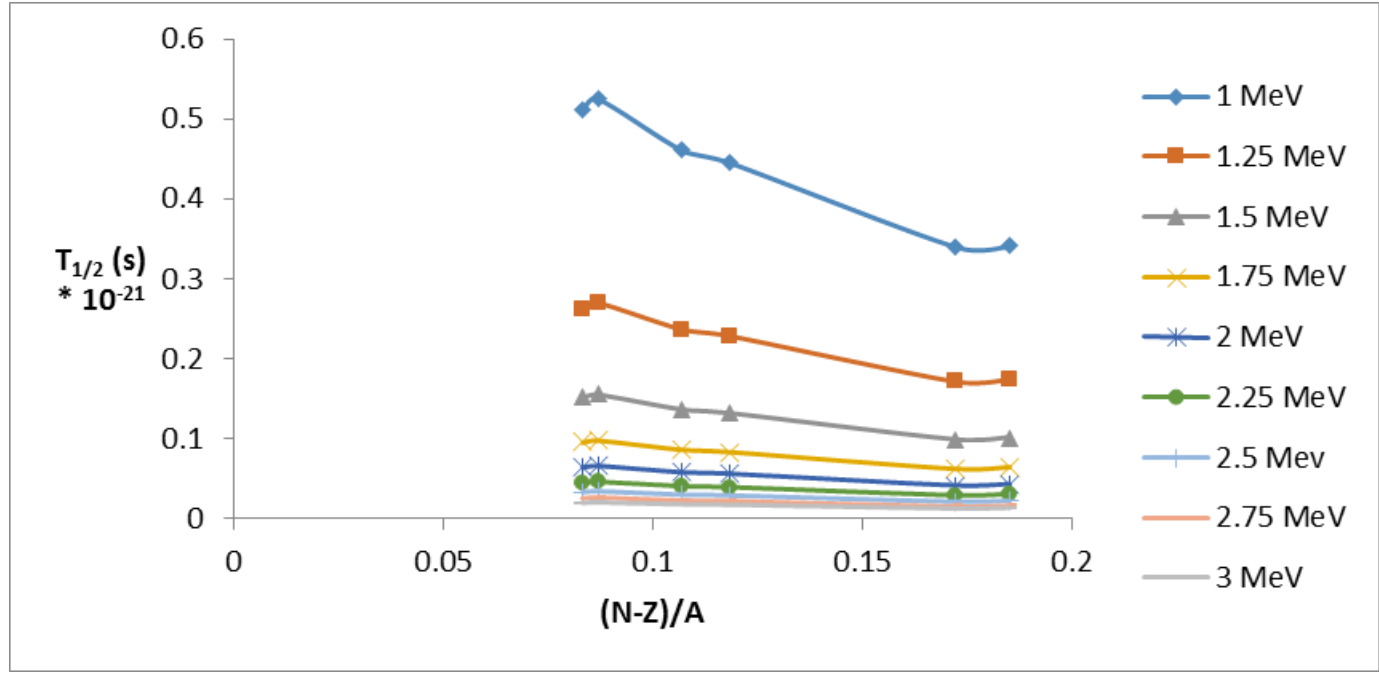

Figure (6): The half-life variation with the asymmetry factor.

After that, the obtained fitting parameters $a, b$ were tested for their gamma energy dependence. The results show a systematic power series variation with the fitting parameters as they are given in Tables (4) and (5) (respectively) and shown in Figures 7 and 8 (respectively).

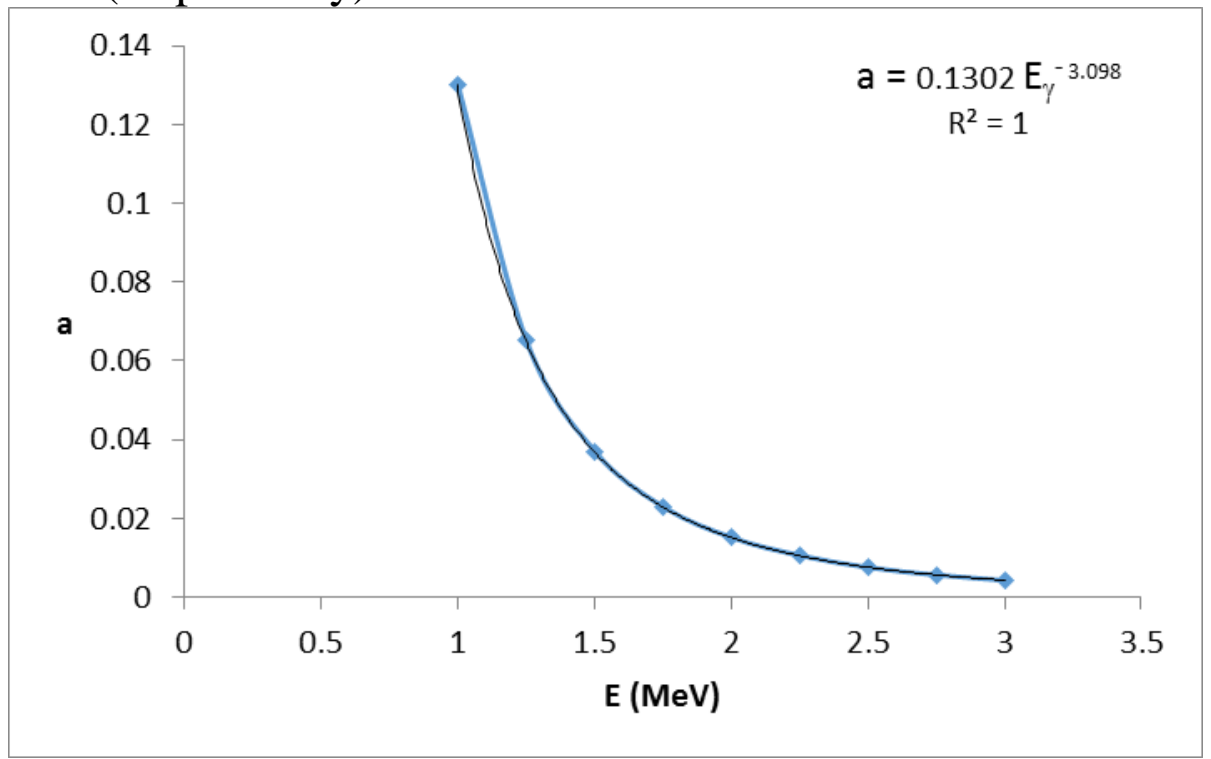

Figure (7): The parameter (a) decreases with the increase of gamma energy.

Table (4): The calculated and new fitting parameters of (a).

\begin{tabular}{|c|c|c|}
\hline $\mathbf{E}_{\gamma}(\mathbf{M e V})$ & Calculated (a) & $\begin{array}{c}\text { Fitting parameter (a) } \\
\mathrm{a}=0.1302 \mathrm{E}_{\gamma}^{-3.098}\end{array}$ \\
\hline 1 & 0.1302 & 0.13 \\
\hline 1.25 & 0.06522 & 0.0652 \\
\hline 1.5 & 0.037075 & 0.0371 \\
\hline 1.75 & 0.022997 & 0.023 \\
\hline 2 & 0.015206 & 0.0152 \\
\hline
\end{tabular}




\begin{tabular}{|c|c|c|}
\hline 2.25 & 0.010557 & 0.0106 \\
\hline 2.5 & 0.007617 & 0.0076 \\
\hline 2.75 & 0.00567 & 0.0057 \\
\hline 3 & 0.00433 & 0.0043 \\
\hline
\end{tabular}

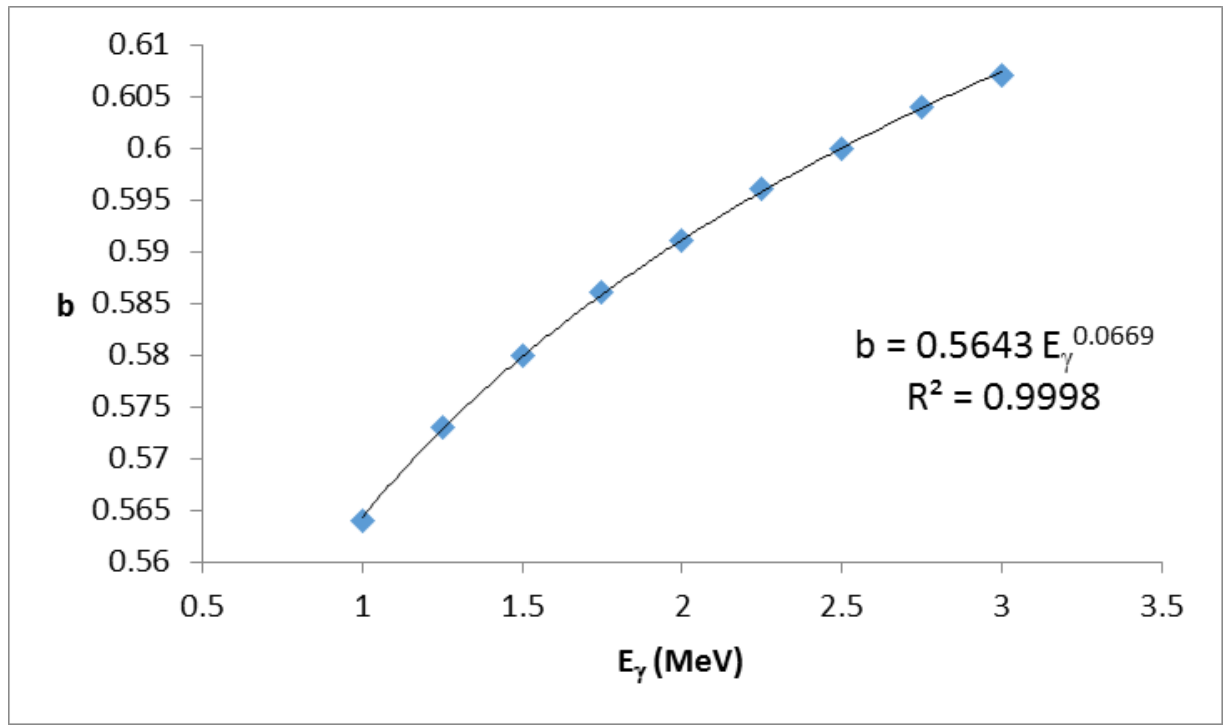

Figure (8): The parameter (b) increases with the increase of gamma energy.

Table (5): The calculated and new fitting parameters of (b).

\begin{tabular}{|c|c|c|}
\hline $\mathrm{E}_{\gamma}(\mathbf{M e V})$ & Calculated (b) & $\begin{array}{c}\text { Fitting parameter (b) } \\
\mathbf{b}=0.5643 \mathrm{E}_{\gamma}^{0.0669}\end{array}$ \\
\hline 1 & 0.5643 & 0.564 \\
\hline 1.25 & 0.572787 & 0.573 \\
\hline 1.5 & 0.579816 & 0.58 \\
\hline 1.75 & 0.585827 & 0.586 \\
\hline 2 & 0.591084 & 0.591 \\
\hline 2.25 & 0.59576 & 0.596 \\
\hline 2.5 & 0.599974 & 0.6 \\
\hline 2.75 & 0.603812 & 0.604 \\
\hline 3 & 0.607337 & 0.607 \\
\hline
\end{tabular}

Thus the new fitting value of constant factors (a) and (b) achieve in formulas listed in Tables (4) and (5) are combined to the formal power expression for the variation of half-life with the asymmetry factor and the following empirical formula has been obtained

$\mathrm{T}_{1 / 2}=0.1302 \mathrm{E}_{\gamma}^{-3.098}(\mathrm{~N}-\mathrm{Z} / \mathrm{A})^{0.5643 \mathrm{E}_{\gamma}{ }^{0.0669}}$

The calculated half-life with the experimental data has been compared as presented in Table (6), a good agreement has been observed. 
Table (6): The experimental data and the calculated half-life which depend on the asymmetric factor $(\mathrm{N}-\mathrm{Z}) / \mathrm{A}$.

\begin{tabular}{|c|c|c|c|c|c|}
\hline \multicolumn{2}{|c|}{$\mathbf{T}_{\mathbf{1} / \mathbf{2}}$ (sec) for $\mathbf{E}_{\gamma}=\mathbf{1 M e V}$} & \multicolumn{2}{|c|}{$\mathbf{T}_{\mathbf{1 / 2}}(\mathbf{s e c}) \mathbf{E}_{\gamma}=\mathbf{2 M e V}$} & \multicolumn{2}{c|}{$\mathbf{T}_{\mathbf{1} / \mathbf{2}}(\mathbf{s e c}) \mathbf{E}_{\gamma}=\mathbf{3 M e V}$} \\
\hline Experiment & Calculate & Experiment & Calculate & Experiment & Calculate \\
\hline 0.5108 & 0.529287 & 0.06385 & 0.06607 & 0.018919 & 0.019589 \\
\hline 0.5255 & 0.5168 & 0.065688 & 0.064438 & 0.019463 & 0.019092 \\
\hline 0.4609 & 0.459305 & 0.057613 & 0.05695 & 0.01707 & 0.016816 \\
\hline 0.4452 & 0.433616 & 0.05565 & 0.053618 & 0.016489 & 0.015806 \\
\hline 0.3401 & 0.351102 & 0.040752 & 0.042982 & 0.01178 & 0.012594 \\
\hline 0.341 & 0.337298 & 0.042625 & 0.041213 & 0.01263 & 0.012062 \\
\hline
\end{tabular}

\section{Half-life and Binding Energy}

The Binding Energy (BE) of the studied nuclei were taken from NDC [7] tabulated in Table (7).

Table (7): Binding energy for the studied gamma-emitting radionuclides.

\begin{tabular}{|c|c|c|c|c|}
\hline Nuclide & $\mathbf{Z}$ & $\mathbf{N}$ & $\mathbf{A}$ & $\begin{array}{c}\text { BE [7] } \\
(\mathbf{M e V})\end{array}$ \\
\hline $\mathrm{Ti}$ & 22 & 26 & 48 & 418.704 \\
\hline $\mathrm{Sc}$ & 21 & 25 & 46 & 396.613 \\
\hline $\mathrm{Mn}$ & 25 & 31 & 56 & 489.347 \\
\hline $\mathrm{Fe}$ & 26 & 33 & 59 & 516.532 \\
\hline $\mathrm{Kr}$ & 36 & 51 & 87 & 747.750 \\
\hline $\mathrm{As}$ & 33 & 48 & 81 & 700.493 \\
\hline
\end{tabular}

The calculated gamma-decay half-life's have been tested for the nuclei BE dependence at the fixed gamma energy steps $(1,1.25,1.5 \mathrm{MeV}, \ldots .3 \mathrm{MeV})$ as tabulated in Table (8) and shown in Figure (9).

The plotted data have been fitted to the power expressions for each studied nuclei as

$$
\mathrm{T}_{1 / 2}=\mathrm{a}(\mathrm{BE})^{-\mathrm{b}}
$$

with $R^{2}=0.9903-0.995$. 
Table (8) Empirical formulae relating the half-life to the BE factor for fixed energies $(1-3 \mathrm{MeV})$ with the correlation coefficient $R^{2}$.

\begin{tabular}{|c|c|c|}
\hline $\begin{array}{c}\mathbf{E}_{\gamma} \\
(\mathbf{M e V})\end{array}$ & $\begin{array}{c}\text { Empirical Formula } \\
\mathrm{T}_{1 / 2}=\mathrm{a}(\mathrm{BE})^{-\mathrm{b}}\end{array}$ & $\mathbf{R}^{2}$ \\
\hline 1 & $\mathrm{~T}_{1 / 2}=38.697(\mathrm{BE})^{-0.72}$ & 0.9903 \\
\hline 1.25 & $\mathrm{~T}_{1 / 2}=21.533(\mathrm{BE})^{-0.734}$ & 0.9929 \\
\hline 1.5 & $\mathrm{~T}_{1 / 2}=13.338(\mathrm{BE})^{-0.745}$ & 0.9942 \\
\hline 1.75 & $\mathrm{~T}_{1 / 2}=8.8964(\mathrm{BE})^{-0.754}$ & 0.9948 \\
\hline 2 & $\mathrm{~T}_{1 / 2}=6.2643(\mathrm{BE})^{-0.763}$ & 0.995 \\
\hline 2.25 & $\mathrm{~T}_{1 / 2}=4.5972(\mathrm{BE})^{-0.77}$ & 0.9949 \\
\hline 2.5 & $\mathrm{~T}_{1 / 2}=3.4857(\mathrm{BE})^{-0.776}$ & 0.9946 \\
\hline 2.75 & $\mathrm{~T}_{1 / 2}=2.7136(\mathrm{BE})^{-0.782}$ & 0.9942 \\
\hline 3 & $\mathrm{~T}_{1 / 2}=2.1591(\mathrm{BE})^{-0.787}$ & 0.9937 \\
\hline
\end{tabular}

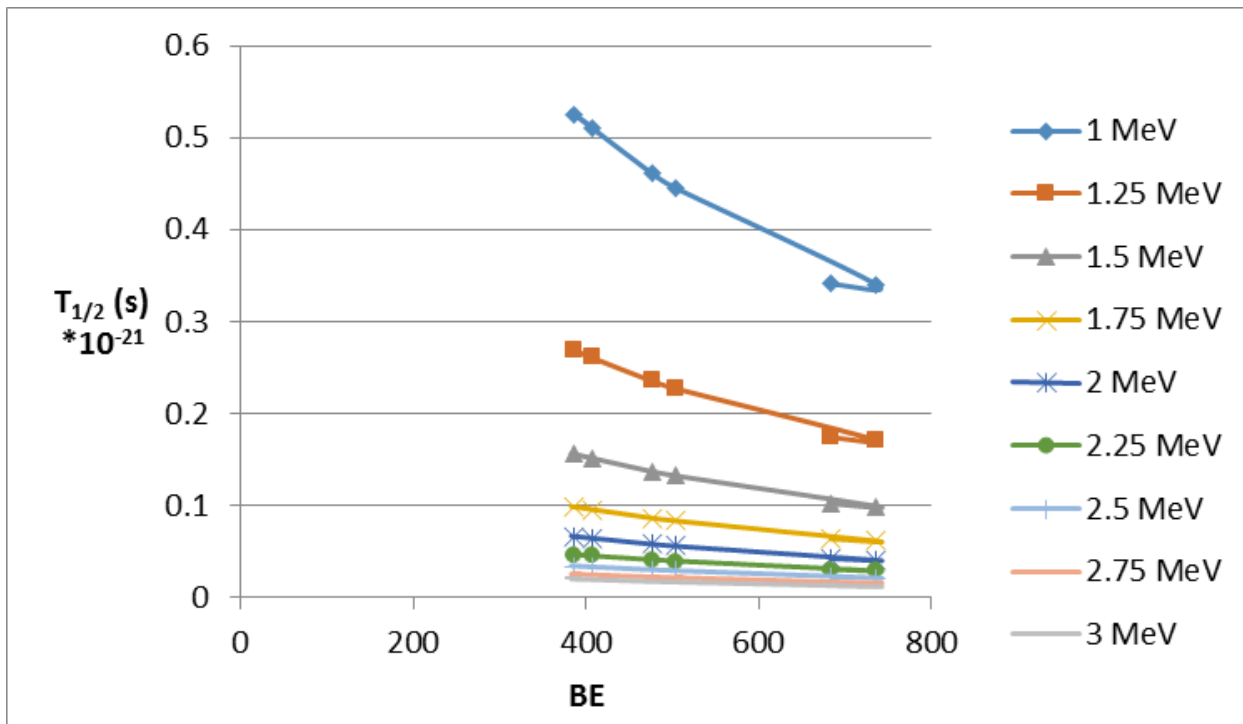

Figure (9): The half-life is inversely proportional to the binding energy. After that, the obtained fitting parameters $a, b$ were tested for their gamma energy dependence. The results show a systematic power series variation with the fitting parameters as they are given in Tables (9) and (10) respectively, and shown in Figures (10) and (11), respectively. 


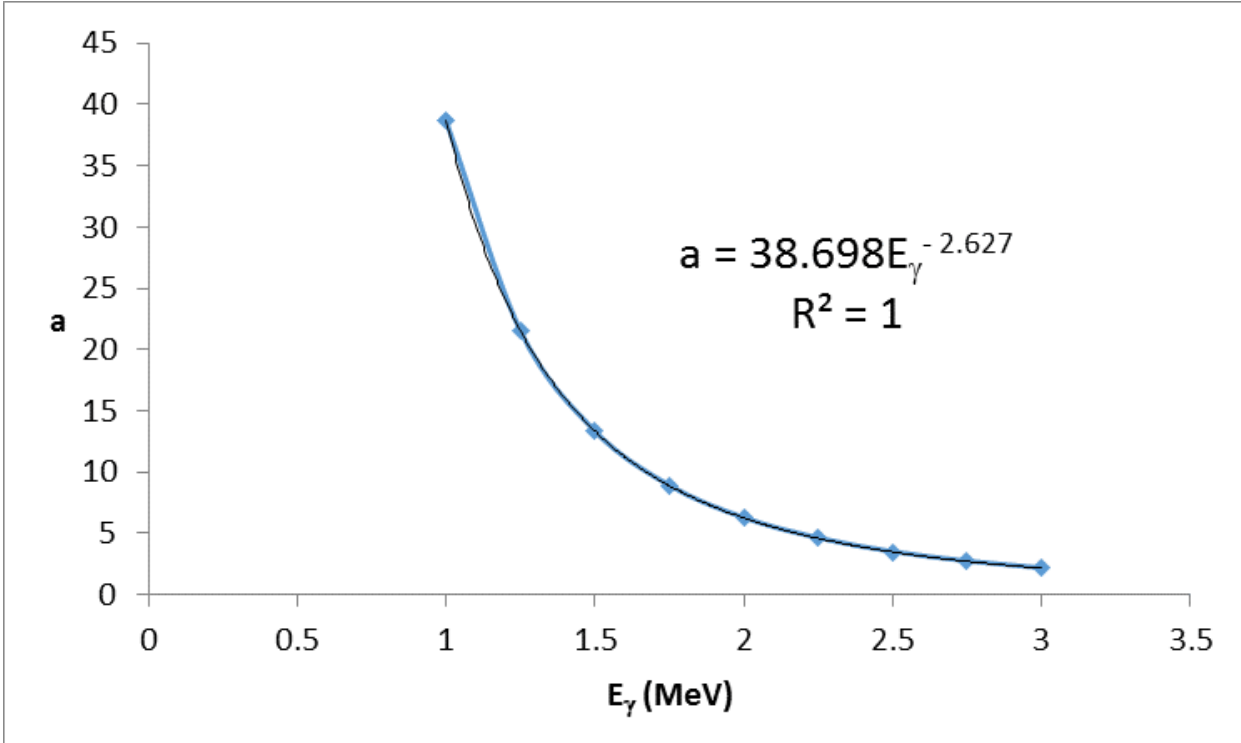

Figure (10): The parameter (a) decreases with the increase of gamma energy.

Table (9) The calculated and new fitting parameters of (a).

\begin{tabular}{|c|c|c|}
\hline $\begin{array}{c}\mathbf{E}_{\gamma} \\
(\mathbf{M e V})\end{array}$ & $\begin{array}{c}\text { Calculated } \\
(\mathbf{a})\end{array}$ & $\begin{array}{c}\text { Fitting parameter } \\
(\mathbf{a})\end{array}$ \\
\hline 1 & 38.698 & $38.698 \mathrm{E}_{\gamma}^{-2.627}$ \\
\hline 1.25 & 21.53307 & 21.533 \\
\hline 1.5 & 13.33819 & 13.338 \\
\hline 1.75 & 8.896672 & 8.8964 \\
\hline 2 & 6.264447 & 6.2643 \\
\hline 2.25 & 4.597323 & 4.5972 \\
\hline 2.5 & 3.485781 & 3.4857 \\
\hline 2.75 & 2.713698 & 2.7136 \\
\hline 3 & 2.159191 & 2.1591 \\
\hline
\end{tabular}




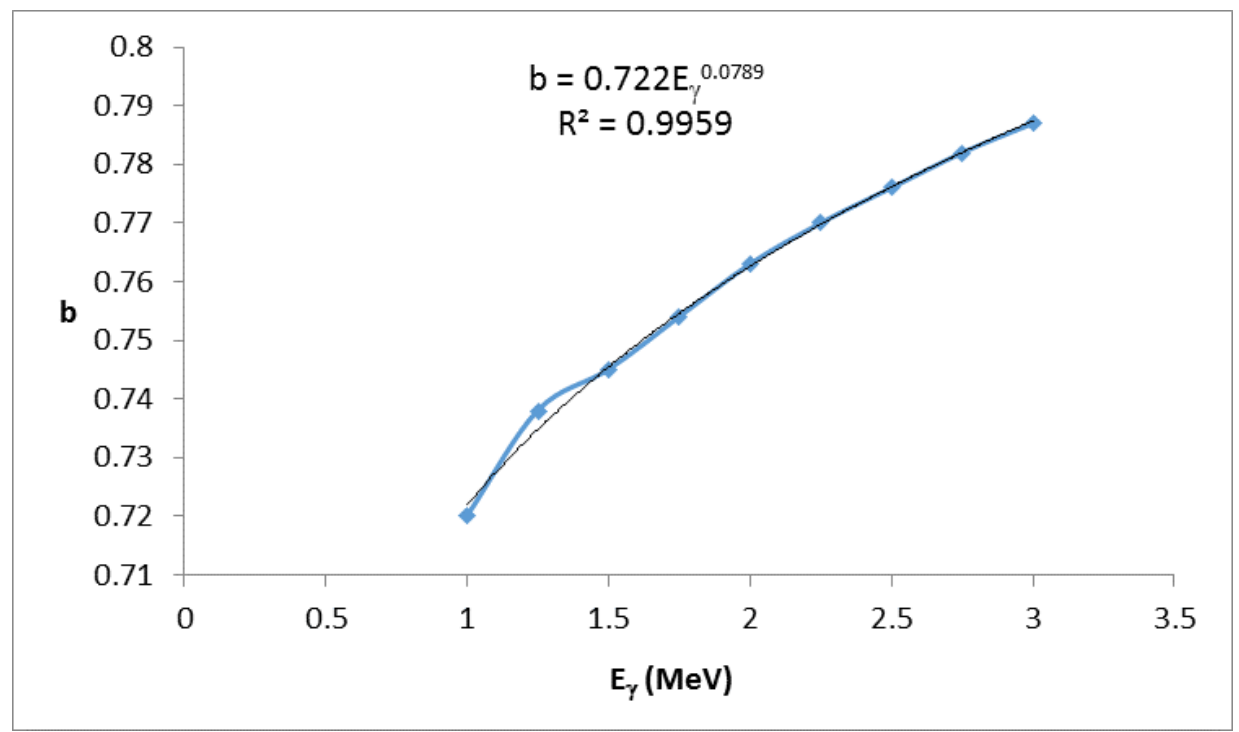

Figure(11): The parameter (b) increases with the increase of gamma energy.

Table (10) The calculated and new fitting parameters of (b).

\begin{tabular}{|c|c|c|}
\hline $\begin{array}{c}\mathrm{E}_{\gamma} \\
(\mathbf{M e V})\end{array}$ & Calculated (b) & $\begin{array}{c}\text { Fitting } \\
\text { parameter (b) } \\
\mathbf{b}^{\text {(b) }} 0.722 \mathrm{E}_{\gamma}{ }^{000789}\end{array}$ \\
\hline 1 & 0.722 & 0.72 \\
\hline 1.25 & 0.734824 & 0.738 \\
\hline 1.5 & 0.745471 & 0.745 \\
\hline 1.75 & 0.754593 & 0.754 \\
\hline 2 & 0.762585 & 0.763 \\
\hline 2.25 & 0.769705 & 0.77 \\
\hline 2.5 & 0.77613 & 0.776 \\
\hline 2.75 & 0.781989 & 0.782 \\
\hline 3 & 0.787376 & 0.787 \\
\hline
\end{tabular}

Thus the new fitting value of constant factors (a) and (b) achieve in formulas listed in Tables (9) and (10) are combined to the formal power expression for the variation of half-life with the BE factor and the following empirical formula has been obtained

$$
\mathrm{T}_{1 / 2}=38.698 \mathrm{E}_{\gamma}^{-2.627}(\mathrm{BE}){ }_{\gamma}^{0.722 \mathrm{E}^{0.0789}}
$$

The calculated half-life with the experimental data has been compared as presented in Table (11), a good agreement has been observed. 
Table (11): The experimental and the calculated half-life which depend on the BE.

\begin{tabular}{|c|c|c|c|c|c|}
\hline \multicolumn{2}{|c|}{$\begin{array}{c}\mathrm{T}_{1 / 2}(\mathrm{sec}) \text { for } \mathrm{E}_{\gamma}= \\
1 \mathrm{MeV}\end{array}$} & \multicolumn{2}{|c|}{$\mathbf{T}_{1 / 2}(\sec ) \mathbf{E}_{\gamma}=2 \mathrm{MeV}$} & \multicolumn{2}{|c|}{$\mathbf{T}_{1 / 2}(\sec ) \mathbf{E}_{\gamma}=3 \mathrm{MeV}$} \\
\hline $\begin{array}{l}\text { Experiment } \\
\text { al }\end{array}$ & $\begin{array}{l}\text { Calculate } \\
\text { d }\end{array}$ & $\begin{array}{l}\text { Experiment } \\
\text { al }\end{array}$ & $\begin{array}{l}\text { Calculate } \\
\text { d }\end{array}$ & $\begin{array}{l}\text { Experiment } \\
\text { al }\end{array}$ & $\begin{array}{l}\text { Calculate } \\
\text { d }\end{array}$ \\
\hline 0.5108 & 0.504908 & 0.06385 & 0.064044 & 0.018919 & 0.019019 \\
\hline 0.5255 & 0.52514 & 0.065688 & 0.066757 & 0.019463 & 0.019851 \\
\hline 0.4609 & 0.450904 & 0.057613 & 0.056831 & 0.01707 & 0.016811 \\
\hline 0.4452 & 0.433519 & 0.05565 & 0.054519 & 0.016489 & 0.016106 \\
\hline 0.3401 & 0.329348 & 0.040752 & 0.040784 & 0.01178 & 0.011935 \\
\hline 0.341 & 0.347496 & 0.042625 & 0.043161 & 0.01263 & 0.012654 \\
\hline
\end{tabular}

\section{Conclusion}

Two empirical formulae have been established to estimate the dependence of the half-life of E1 gamma-decay transitions for the studied isotopes ${ }_{22} \mathrm{Ti}^{48},{ }_{21} \mathrm{Sc}^{46}$, ${ }_{25} \mathrm{Mn}^{56},{ }_{26} \mathrm{Fe}^{59},{ }_{36} \mathrm{kr}^{87},{ }_{33} \mathrm{As}^{81}$ ). The first formulae combine the half-life with both of gamma energy and the asymmetry factor, and the second combines the transition energy with the binding energy. Good agreements have been observed between the calculated half-life and the experimental ones.

\section{References}

1. S.A. Ibrahim, A.A. Abbass, S.A. Ahmed, and N.T.Abd-Al-Hameed, Calculation of the Reduced Transition Probabilities M (E2) for even-even Tungsten nuclide (74W)) A=180-186), J. of Chem. , Bio, Physical Science, volume 5, ( 2015) 3379-3383.

2. Karl H. L. - Weinheim, Nuclear and Radiochemistry: fundamentals and applications, New York; Basel; Cambridge: VCH, (1997).

4. Walter E. Meyerhof, Elements of Nuclear Physics, New York, Copyright by McGraw- Hill (1967).

3. Joseph W. Kennedy and Edward s. Macias, Nuclear And Radiochemistry, 3rd Edition, New York and Chicester . Copyright by John Wiley \& Sons (1981).

5. Kenneth S. Krane, Introductory Nuclear Physics, $2^{\text {nd }}$ edition . New York, (1955).

6. https://www-nds.iaea.org/ensdf_base_files/, International Atomic Energy Agency - Nuclear Data Section (2007-2017).

7. http://www.nndc.bnl.gov/nudat2/reCenter.jsp? $\mathrm{z}=22 \& \mathrm{n}=26$, National Nuclear Data Center,

Brookhaven National Laboratory, based on ENSDF and the Nuclear Wallet Cards (2016). 